\title{
EXTRANJEROS EN SITUACIÓN MIGRATORIA IRREGULAR Y SU DERECHO A CONTRAER MATRIMONIO EN CHILE
}

\author{
ALIENS WITH IRREGULAR STATUS AND THEIR RIGHT TO \\ MARRY IN CHILE
}

\author{
ARTURO IBÁÑEZ LEÓN* \\ SUSAN TURNER SAELZER**
}

\section{RESUMEN}

El fenómeno de la constitucionalización del derecho de familia se traduce no solo en importantes consecuencias en la forma de interpretar y aplicar las normas legales de dicha rama del derecho, sino que también plantea ciertas cuestiones problemáticas. Este artículo se ocupa precisamente de una de dichas cuestiones: los eventuales conflictos entre la regulación legal del matrimonio y el derecho constitucional a contraer matrimonio, conflictos que surgen cuando quien pretende contraer matrimonio en Chile es un extranjero cuya situación migratoria es irregular. En particular, este artículo analiza críticamente los argumentos desplegados por la Corte Suprema en el debate jurisprudencial que ha tenido lugar en sede de acción de protección.

Palabras clave: Matrimonio, Regulación legal del matrimonio, Derecho constitucional al matrimonio, Extranjeros en situación irregular, Derecho de familia, Jurisprudencia de la Corte Suprema.

\footnotetext{
*Licenciado en Ciencias Jurídicas y Sociales, Universidad de Chile. Magíster Juris, Universidad de Oxford, Reino Unido. Profesor de Derecho Civil, Universidad Adolfo Ibáñez, Santiago, Chile. Correo electrónico: arturo.ibanez@uai.cl. Código Orcid: https://orcid.org/0000-0001-8117-160X

**Licenciada en Ciencias Sociales y Jurídicas, Universidad de Chile. Doctora en Derecho, Universidad de Göttingen, Alemania. Profesora de Derecho Civil, Universidad Austral de Chile, Valdivia, Chile. Correo electrónico: sturner@uach.cl. Código Orcid: https://orcid.org/0000-0003-2476-4294

Artículo recibido para su evaluación el 17 de agosto de 2020, y aprobado para su publicación el 30 de noviembre de 2020.
} 


\section{ABSTRACT}

The phenomenon of understanding legal rules of family law in light of the Constitution has consequences not only for the way in which those legal rules are interpreted and applied. It also poses some relevant controversies. This article deals with one of such controversies: the posssible conflicts between the legal regulation of marriage and the constitutional right to marry. Such a conflict arises when an alien with irregular status wants to marry in Chile. In particular, this article critically analyses the reasoning of the Supreme Court in decisions concerning constitutional actions of protection.

Keywords: Marriage, Legal regulation of marriage, Constitutional right to marry, Aliens with irregular status, Family law, Supreme Court jurisprudence.

\section{INTRODUCCIÓN}

Los efectos del fenómeno de constitucionalización del derecho de familia nacional han sido ampliamente reconocidos por la doctrina. La identificación de las consecuencias de este fenómeno en el derecho privado en general, consistentes en la interpretación conforme a la constitución, la derogación de las normas contrarias o contradictorias con esta última y de integración de los tratados internacionales como fuente directa de derecho, ${ }^{1}$ ha permitido analizar la evolución de esta rama del derecho civil con un prisma novedoso y, también, visualizar los riesgos a los que el fenómeno somete a los estatutos legales de las instituciones civiles.

Dichos riesgos surgen porque la interpretación conforme a la Constitución y la ampliación del catálogo de derechos fundamentales a través de la incorporación de tratados internacionales que versan sobre ellos, genera fricciones al interior de la reglamentación de rango legal, no solo dentro de la civil sino también en otros ámbitos del derecho. ${ }^{2}$

\footnotetext{
${ }^{1}$ La identificación de estas tres consecuencias de la constitucionalización del derecho privado corresponde a la efectuada por Ramón Domínguez ÁguiLA en su precursor trabajo: DomínguEz, Ramón, "Aspectos de la constitucionalización del Derecho Civil chileno", Revista de Derecho y Jurisprudencia, 1996, Tomo XCIII, Nro. 3, pp. 114-125.

${ }^{2}$ En este sentido, LATHROP identifica la existencia de tensiones entre las constituciones nacionales y los estatutos legales del derecho de familia a partir del momento en que las "constituciones latinoamericanas
} 
Este trabajo aborda una de esas zonas de fricción: el estatuto legal del matrimonio confrontado con un derecho constitucional reconocido en Chile sin estar expresamente consagrado en la Constitución Política de la República (en adelante, CPR) pero que se ha incorporado a ella a través su art. 5 inciso $2^{\circ}$, el derecho al matrimonio o derecho a contraer matrimonio.

Este derecho ha estado presente en el debate nacional en torno al matrimonio igualitario o matrimonio entre personas del mismo sexo. Sin embargo, en los últimos años ha aflorado en otro ámbito sensible: en el del ejercicio de derechos fundamentales por parte de extranjeros cuya situación migratoria es irregular. La constitución "invasiva" o "entrometida" en las relaciones familiares de estas personas, ${ }^{3}$ ha hecho visible una pugna entre el estatuto legal del matrimonio y el derecho a contraer matrimonio de estos inmigrantes ${ }^{4}$ que se ha ventilado en sede de recurso de protección.

La primera parte del trabajo abordará el derecho a contraer matrimonio, tanto en cuanto a sus fuentes, contenido y consagración legal. A continuación, la segunda parte analizará el cuerpo de sentencias dictadas por la Corte Suprema (en adelante, CS) a partir del año 2015, en que el derecho a contraer matrimonio de personas extranjeras cuya situación migratoria es irregular ha estado en el centro del debate

\section{EL DERECHO A CONTRAER MATRIMONIO O IUS CONNUBII}

\section{Fuentes y contenido del derecho a contraer matrimonio}

La CPR chilena es muy parca en cuanto a disposiciones relativas a la familia y de ahí que, desde ese punto de vista, pueda catalogarse como una constitución minimalista. ${ }^{5}$ Dicho rasgo determina que en nuestro

comienzan a proteger, de manera más o menos explícita e integral a la familia". LATHROP, Fabiola, "Constitucionalización y Jurisprudencia Constitucional en el Derecho de Familia chileno", Estudios Constitucionales, 2017, Año 15 nº 1, p. 336.

${ }^{3}$ Lathrop, Fabiola y EspeJo, Nicolás, "Hacia la constitucionalización del derecho de familia en Latinoamérica", Revista de derecho privado Universidad del Externado, 2020, n 38, p. 94.

${ }^{4}$ Se trata de una pugna que tiene antecedentes en otros países receptores de migrantes. Así, por ejemplo, en 1996 se publicó un trabajo sobre el ejercicio del derecho al matrimonio en España y en ese momento, la autora identificaba dos tipos de obstáculos para los extranjeros: las imposiciones ideológicas impuestas por el país receptor y las interferencias de sus normas de extranjería o nacionalidad. ANDROHER, Salomé, "El derecho a contraer matrimonio en la emigración”, Migraciones, 1996, nº 0, p. 108-109.

${ }^{5}$ ZúÑIGA, Yanira, Turner, Susan, "Sistematización comparativa de la regulación de la familia en las 
país cobre especial relevancia aquella manifestación del fenómeno de constitucionalización relativo a la incorporación al ordenamiento interno de fuentes de carácter internacional. Es lo que ocurre con el derecho a contraer matrimonio que, vía art. 5 de la CPR, como ya se indicó, se incorpora al catálogo chileno de derechos fundamentales amparados por la constitución. Estas fuentes son las siguientes:

a) En el sistema de Naciones Unidas:

Arts. 16.1 y 2 de la Declaración Universal de los Derecho Humanos (1948): Los hombres y las mujeres, a partir de la edad núbil, tienen derecho, sin restricción alguna por motivos de raza, nacionalidad o religión, a casarse y fundar una familia, y disfrutarán de iguales derechos en cuanto al matrimonio, durante el matrimonio y en caso de disolución del matrimonio.

Sólo mediante libre y pleno consentimiento de los futuros esposos podrá contraerse el matrimonio.

Art. 10.1. del Pacto Internacional de Derechos Económicos, Sociales y Culturales (1966): El matrimonio debe contraerse con el libre consentimiento de los futuros cónyuges.

Arts. 23.2 y 3. del Pacto Internacional de Derechos Civiles y Políticos (1966): Se reconoce el derecho del hombre y de la mujer a contraer matrimonio y a fundar una familia si tienen edad para ello. El matrimonio no podrá celebrarse sin el libre y pleno consentimiento de los contrayentes.

Art. 16.1 de la Convención sobre la eliminación de todas las formas de discriminación contra la mujer (1979): Los Estados Partes adoptarán todas las medidas adecuadas para eliminar la discriminación contra la mujer en todos los asuntos relacionados con el matrimonio y las relaciones familiares $\mathrm{y}$, en particular, asegurarán, en condiciones de igualdad entre hombres y mujeres: El mismo derecho para contraer matrimonio; El mismo derecho para elegir libremente cónyuge y contraer matrimonio sólo por su libre albedrío y su pleno consentimiento.

b) En el sistema americano de Derechos Humanos:

Arts. 17.2 y 3 de la Convención Americana sobre Derechos Humanos (1969) (en adelante, CADH): Se reconoce el derecho del hombre y la mujer a contraer matrimonio y a fundar una familia si tienen la edad y las condiciones requeridas para ello por las leyes internas, en la medida

constituciones latinoamericanas", Revista de Derecho Universidad Católica del Norte, 2013, Año 20 $\mathrm{n}^{\circ} 2$, pp. 277 y 279. 
en que éstas no afecten al principio de no discriminación establecido en esta Convención. El matrimonio no puede celebrarse sin el libre y pleno consentimiento de los contrayentes.

A partir de estas normas, pueden extraerse algunas particularidades de este derecho. ${ }^{6}$

En primer lugar, el derecho a contraer matrimonio se regula normalmente en relación con el derecho a fundar una familia, si bien ambos derechos pueden operar de manera independiente. ${ }^{7}$ Es decir, no cabe duda de que el matrimonio es un acto jurídico capaz de originar una familia. Sin embargo, no constituye el fundamento único y necesario de una familia. En el derecho internacional de los derechos humanos, pese a que esta constituye un elemento natural y fundamental de la sociedad, no siempre fue claro qué debía entenderse por familia y, por ende, qué importaba el deber de protegerla. Terminó imponiéndose una concepción amplia de la familia, ${ }^{8}$ en la que no se identifica un modelo familiar único. ${ }^{9}$

Por otra parte, al momento de identificar al titular del derecho a contraer matrimonio, la mayoría de las normas internacionales aluden al "hombre y la mujer". Esta manera de identificar a los titulares del derecho tiene, desde luego, una explicación histórica. Los instrumentos internacionales que identifican al hombre y a la mujer como sujetos del derecho son todos

\footnotetext{
${ }^{6}$ TuRner, Susan, "Familia, matrimonio y derechos. El derecho a contraer matrimonio", en: ElorriagA, F. (Ed.), Estudios de Derecho Civil VII, Thomson Reuters, Santiago, 2012, pp. 32-33.

${ }^{7}$ CABanillas, Antonio, "Derecho a la Constitución de la familia y a su protección", Revista Electrónica Iberoamericana, 2019, volumen 13, ed. especial, p. 15.

${ }^{8}$ En este sentido, algunos instrumentos internacionales de derechos humanos amplían expresamente el concepto de familia aludido en sus normas. Por ejemplo, la Convención Internacional sobre la Protección de los Derechos de todos los Trabajadores Migratorios y de sus Familiares. Este tratado regula expresamente la situación de los trabajadores migratorios y de los "miembros de su familia", esto es, aquellas "personas casadas con los migrantes, o que tienen una relación que, por ley, es equivalente a un matrimonio, tanto como a sus hijos dependientes, así como otras personas dependientes que hayan sido reconocidas como miembros de la familia por ley o acuerdos bilaterales o multilaterales entre los Estados miembros" (artículo 4).

${ }^{9}$ Beloff, Mary, “Art. 17. Protección a la Familia”. En: Steiner, C.; Fuchs, M. (Eds.), Convención Americana de Derechos Humanos. Comentario, Konrad Adenauer Stiftung, Bogotá, segunda edición, 2019, p. 484-485. Para justificar esta aseveración, la autora cita varios pronunciamientos de organismos de derechos humanos: la Observación General n. ${ }^{\circ} 19$ del Comité de Derechos Humanos de la ONU de 1990, "Protección a la Familia, el Derecho al Matrimonio y la Igualdad de los Esposos (artículo 23)", párrafo 2 y la Observación General n. ${ }^{\circ} 16$ del mismo organismo, de 1988, "Derecho a la intimidad (artículo 17)"; la Recomendación General n² 21 de 1994, del Comité para la Eliminación de la Discriminación contra la Mujer, "La igualdad en el matrimonio y en las relaciones familiares"; y la Observación General n 7 del Comité de los Derechos del Niño, de 2005, "Realización de los derechos del niño en la primera infancia", párrafos 15 y 19.
} 
anteriores a 1970 y se podría presumir, entonces, que recogían la práctica social del matrimonio heterosexual. ${ }^{10}$

En relación con la categoría a la que pertenecería el derecho, algunos autores han sostenido que él constituye una manifestación de la autonomía de toda persona. ${ }^{11}$ Otros, en cambio, buscan su fundamento en el derecho fundamental a la libertad ${ }^{12}$ o en el libre desarrollo de la personalidad. ${ }^{13}$

En cuanto a su aplicación, el derecho a contraer matrimonio reconoce como válidas ciertas condiciones de ejercicio. La necesidad de que medie un consentimiento válido entre las personas que celebran el matrimonio y la exigencia de contar con cierta edad para contraerlo, se especifican en algunos instrumentos internacionales. ${ }^{14}$ En otros, en cambio, se alude de manera genérica a las condiciones que establezcan las leyes nacionales o internas. ${ }^{15}$ En este sentido, se trata de un derecho no absoluto pues admite un régimen legal de requisitos y condiciones de ejercicio. ${ }^{16}$

Cabe preguntarse, entonces, acerca del grado de libertad que cada legislador tendría al momento de configurar su estatuto matrimonial, en el sentido de si podría establecer requisitos o condiciones que limiten el

\footnotetext{
${ }^{10}$ Por el contrario, en las normas comunitarias europeas, los derechos reconocidos tienen como titular a "toda persona". El art. Art. 9 de la Carta de Derechos Fundamentales de la Unión Europea del año 2000 , consagra el derecho a contraer matrimonio y a fundar una familia de toda persona, sin distinción alguna entre hombre y mujer.

${ }^{11}$ Fernández, Francisco, El sistema constitucional español, Editorial Dykinson, Madrid, 1992, p. 234.

${ }^{12}$ Roca I Trias, Encarna, Familia y cambio social (de la “casa” a la persona), Civitas, Madrid, 1999, p. 92 y sgtes. La autora distingue una faceta positiva de la libertad, en virtud de la que toda persona sería libre para decidir si contraer matrimonio o no y la persona con el que lo contrae; y una faceta negativa, que ampararía la libertad de la persona de no contraer matrimonio.

${ }^{13}$ Molina, Carlos; CARrillo, Yudi, "El matrimonio de parejas del mismo sexo y la Corte Constitucional de Colombia", Revista de Derecho (Valdivia), 2018, vol. XXXI n 1, p. 88. Los autores aluden a la sentencia de la Corte Constitucional colombiana C-577-2011, referida al matrimonio homosexual.

${ }^{14}$ Reafirmando estos dos requisitos para el reconocimiento jurídico de un matrimonio, la "Convención sobre el consentimiento para el matrimonio, la edad mínima para contraer matrimonio y el registro de los matrimonios" del año 1962, expresa en su art. 1: "No podrá contraerse legalmente matrimonio sin el pleno y libre consentimiento de ambos contrayentes.." y en el art. 2: "Los Estados partes en la presente Convención adoptarán las medidas legislativas necesarias para determinar la edad mínima para contraer matrimonio".

${ }^{15}$ En el ámbito europeo, el Convenio Europeo para la Protección de los Derechos y de las Libertades Fundamentales de 1950 establece en su art. 12: "Derecho a contraer matrimonio. A partir de la edad núbil el hombre y la mujer tienen derecho a casarse y a fundar una familia según las leyes nacionales que rijan el ejercicio de este derecho". Por su parte, la Carta de Derechos Fundamentales de la Unión Europea de 2000, consagra en su art. 9: Derecho a contraer matrimonio y a fundar una familia. El derecho a contraer matrimonio y a fundar una familia son garantizados según las leyes nacionales que regulan su ejercicio."

${ }^{16}$ Cabanillas, cit. (n. 7), p. 15; Roca I Trias, cit. (n. 12), pp. 101 y 102.
} 
ejercicio del derecho, distintas de las relativas al consentimiento y a la edad.

\section{La configuración del derecho a contraer matrimonio a nivel legal}

En aquellos ordenamientos en que la constitución nacional consagra el derecho a contraer matrimonio, resulta evidente que queda entregado al legislador respectivo el desarrollo de los requisitos o condiciones necesarias para su ejercicio. Así, por ejemplo, en España y a partir del art. 32.2 de la Constitución Española (en adelante, $\mathrm{CE}$ ), se ha dicho que se trata de un derecho de configuración legal, en cuyo desarrollo el legislador está obligado a respetar el contenido esencial del derecho, según el art. 53.1 de la $\mathrm{CE},{ }^{17}$ además de desarrollar los contenidos mínimos indicados en la propia norma ${ }^{18}$ esto es, formas del matrimonio, edad y capacidad para contraerlo, causas de separación, disolución y sus efectos. El legislador estaría facultado para establecer requisitos y prohibiciones para su ejercicio únicamente en la medida que no sean irracionales. ${ }^{19}$

Para el caso de Chile, y en ausencia de una norma constitucional que consagre el derecho a contraer matrimonio, la tarea del legislador debe ajustarse a lo establecido en la $\mathrm{CADH}$, en el sentido que el reconocimiento del derecho del hombre y la mujer a contraer matrimonio y a fundar una familia podría limitarse en atención a la edad de los contrayentes y al cumplimiento de otras "condiciones requeridas para ello por las leyes internas", pero con una restricción tajante. En efecto, ninguna limitante o condición legal podría afectar "al principio de no discriminación establecido en esta Convención", según el texto de la norma. ${ }^{20}$

Así lo ha destacado la Comisión Interamericana de DDHH: "El

${ }^{17}$ Art. 53.1 CE: "Los derechos y libertades reconocidos en el Capítulo segundo del presente Título vinculan a todos los poderes públicos. Sólo por ley, que en todo caso deberá respetar su contenido esencial, podrá regularse el ejercicio de tales derechos y libertades, que se tutelarán de acuerdo con lo previsto en el artículo 161, 1, a)".

18 AcuÑa, Sara, "El derecho a contraer matrimonio y el derecho a formar una familia en los textos internacionales de derechos humanos y en la Constitución española de 1978". En: Morán, Gloria (Ed.), Cuestiones actuales de derecho comparado, Ediciones Universidade da Coruña, España, 2003, p. 229.

${ }^{19}$ Roca i Trias, cit. (n. 12), pp. 101 y 102.

${ }^{20}$ En esta perspectiva, el art. 2 inc. $1^{\circ}$ de la Ley de Matrimonio Civil vigente cumple con estas exigencias pues indica: "La facultad de contraer matrimonio es un derecho esencial inherente a la persona humana, si se tiene edad para ello. Las disposiciones de esta ley establecen los requisitos para asegurar el libre y pleno consentimiento de los contrayentes." 
derecho a contraer matrimonio y fundar una familia está sujeto a ciertas condiciones del derecho nacional, aunque las limitaciones que por esa vía se introducen no deben ser tan restrictivas que se dificulte la propia esencia del derecho. (...) El artículo 17 (4) de la CADH es la 'aplicación concreta' del principio general de igual protección y no discriminación en el matrimonio del artículo 24". ${ }^{21}$

En nuestro país se da la particularidad de que existe una consagración del derecho a contraer matrimonio a nivel legal, sin apoyo, como se dijo, en los derechos fundamentales recogidos expresamente por la CPR. En efecto, el art. 2 inciso $1^{\circ}$, de la Ley de Matrimonio Civil (Ley 19.947, 2004, en adelante, LMC), en un lenguaje propio del derecho constitucional, establece que "La facultad de contraer matrimonio es un derecho esencial inherente a la persona humana, si se tiene edad para ello". ${ }^{22}$

De esta norma se ha destacado su carácter de libertad fundamental, tanto como libertad positiva como negativa, con notas de esencialidad e inherencia a la persona humana, vinculada directamente con las Bases de la Institucionalidad de la CPR, pues en la medida que la formación de una familia basada en el matrimonio constituya una forma de conseguir el mayor desarrollo espiritual y material posible, el Estado está obligado a su respeto y promoción como parte del bien común, según el art. 1 de la CPR. Este fundamento constitucional de la libertad en que se traduce el derecho a contraer matrimonio permite hacer aplicable a su respecto la garantía del art. $19 \mathrm{n}^{\circ} 26$ de la CPR y, por consiguiente, ningún precepto legal que la regule podría afectarla "en su esencia" ni imponerle "condiciones, tributos o requisitos que impidan su libre ejercicio". En otras palabras, cualquier

${ }^{21}$ Corte Interamericana de Derechos Humanos (CIDH). Caso María Eugenia Morales contra Guatemala, Informe Final. Citado por BADILLA, Ana Elena, El derecho a constitución y la protección de la familia en la normativa y la jurisprudencia del Sistema Interamericano de Derechos Humanos, Editorial Porvenir, San José, 1996, p. 109-110. La autora relaciona esta cita con el art. 29 de la Convención que señala: "Ninguna disposición de la presente Convención puede ser interpretada en el sentido de: a. permitir a alguno de los Estados partes, grupo o persona, suprimir el goce y ejercicio de los derechos y libertades reconocidos en la Convención o limitarlos en mayor medida que la prevista en ella (...)”.

${ }^{22}$ Esa norma recibió críticas durante los primeros años de vigencia de la LMC, en el sentido de carecer de toda función normativa y más bien, reducirse a una declaración poética, debido a que su mera declaración como derecho esencial no le confiere rango constitucional y por consiguiente, no resulta vinculante para el propio legislador, además de ser inconsistente con el uso de la expresión "derecho esencial" en la Constitución. Se le atribuyó la intención de relevar la importancia del matrimonio en el marco de una ley que aceptaba su terminación a través del divorcio. Aldunate, Eduardo, "El derecho esencial a contraer matrimonio" en: VIDAL, Álvaro (ed.), El nuevo derecho chileno del matrimonio, Editorial Jurídica, Santiago, 2006, p. 44, 46 y 47. 
limitación al derecho debe ser excepcional. ${ }^{23}$

Por otra parte, su naturaleza de libertad fundamental explicaría que la LMC contemple para este derecho un recurso directo al juez, ${ }^{24}$ al estilo de la acción de protección del art. 20 de la CPR. Así, el segundo inciso del art. 2 de la LMC establece una acción popular ${ }^{25}$ que cualquier persona puede ejercer si por un acto de un particular o de una autoridad, el derecho sea negado o restringido arbitrariamente. En cualquier caso, el ejercicio de esta acción no excluiría la procedencia de la protección constitucional. ${ }^{26}$

Corresponde, entonces, verificar si el actual estatuto legal del matrimonio en Chile cumple con las condiciones impuestas por su condición de derecho fundamental. Los cuestionamientos en esta materia no se han presentado a propósito de los requisitos estrictos y taxativos contemplados por la LMC sino que con respecto a las condiciones impuestas en normas que están fuera del derecho de familia, específicamente, en el estatuto de extranjería. La vía para reclamar de una afectación ilegítima no ha sido el recurso especial previsto por el art. 2 inciso $2^{\circ}$ de la LMC sino el recurso de protección constitucional.

\section{JURISPRUDENCIA DE LA C.S. SOBRE EL DERECHO A CONTRAER MATRIMONIO DE LOS EXTRANJEROS CON SITUACIÓN MIGRATORIA IRREGULAR}

Tal como se adelantara, el derecho a contraer matrimonio de los inmigrantes en situación irregular ha dado lugar a una jurisprudencia de los tribunales superiores nacionales que no ha logrado uniformarse. La controversia jurídica se ha plasmado en sendos recursos de protección interpuestos por personas extranjeras a las que se les ha denegado la posibilidad de contraer matrimonio en Chile por encontrarse en el territorio nacional de manera ilegal. Esta privación de su derecho importaría, así se deduce de los argumentos de los recurrentes, una afectación esencial del mismo.

\footnotetext{
${ }^{23}$ Barrientos, Javier; Novales, Aranzazu, Nuevo derecho matrimonial chileno, Lexis Nexis, Santiago, 2004, pp. 146-151.

${ }^{24}$ Rodríguez, María Sara, Manual de Derecho de Familia, Editorial Jurídica, Santiago, 2017, p. 140.

${ }^{25}$ Lepín, Cristián, Derecho familiar chileno, Thomson Reuters, Santiago, 2017, p. 84.

${ }^{26}$ Barrientos; Novales, cit. (n. 23), p.155.
} 


\section{La decisión administrativa contra la cual se ha recurrido de protección}

El artículo 76 del Decreto Ley $\mathrm{N}^{\circ} 1.094$ (1975), del Ministerio del Interior (en adelante e indistintamente "Ley de Extranjería" o "D.L. 1.094") establece que "los servicios y organismos del Estado o Municipales deberán exigir a los extranjeros que tramiten ante ellos asuntos de la competencia de esos servicios, que previamente comprueben su residencia legal en el país y que estén autorizados o habilitados para realizar el correspondiente acto o contrato".

Sobre la base de dicha norma, algunos Oficiales del Servicio de Registro Civil e Identificación (en adelante e indistintamente "el Registro Civil") se han negado a autorizar la celebración de matrimonios en Chile de extranjeros que no pueden probar su residencia legal en el país. Es decir, la tensión está en la relación entre el alcance de la norma del artículo 76 de la Ley de Extranjería en relación con las normas del derecho matrimonial chileno, en particular, con las normas de la LMC que establecen y regulan los requisitos para contraer matrimonio.

Del análisis de los fundamentos esgrimidos por el Registro Civil en apoyo de su negativa, en el marco de acciones constitucionales de protección interpuestas en su contra por los afectados, dos son los puntos fundamentales que cabe destacar y que configuran el núcleo de su argumentación.

En primer lugar, el Registro Civil ha sostenido que los extranjeros que pretendan contraer matrimonio en Chile deben cumplir no solo con los requisitos previstos en la $\mathrm{LMC}$, sino que además deben probar que cuentan con residencia legal en Chile, en conformidad al ya referido artículo 76 de la Ley de Extranjería, es decir, deben establecer que su situación migratoria en Chile se encuentra regularizada.

Y, en segundo lugar, el Registro Civil ha señalado que los extranjeros que pretendan celebrar matrimonio en Chile deben probar su residencia legal en el país por medio de la respectiva cédula de identidad otorgada en conformidad a las normas pertinentes de extranjería, exigencia que fluye de lo establecido en el artículo 5 del Decreto Supremo N597 (1984), del Ministerio del Interior, que contiene el Reglamento de Extranjería (en adelante e indistintamente "el Reglamento de Extranjería"), en relación con el artículo 92 del Decreto con Fuerza de Ley $\mathrm{N}^{\circ} 2.128$ (1930), del Ministerio de Justicia, que contiene el Reglamento Orgánico del Servicio de Registro Civil, norma que dispone que antes de proceder a la inscripción que corresponda, el Oficial del Registro Civil debe comprobar la identidad 
del compareciente o contrayentes y dejar constancia de los medios de dicha comprobación.

En suma, al argumentar en la forma recién descrita, el Registro Civil ha entendido que el artículo 76 de la Ley de Extranjería, aplicado al extranjero que quiere celebrar matrimonio en Chile, establece un requisito adicional a los requisitos establecidos en la LMC: que el extranjero pruebe su residencia legal en el país mediante la exhibición de la correspondiente cédula de identidad otorgada en conformidad a las normas de extranjería pertinentes. Por ello, el extranjero que permanece irregularmente en Chile no podría contraer matrimonio en el país. Esta interpretación del alcance del artículo 76 de la Ley de Extranjería constituye el núcleo del debate respecto del cual se ha litigado, formulándose diversos argumentos en pro y en contra de la misma. Del análisis de los fallos de la CS sobre la materia, surgen las dos posturas enfrentadas: aquella con arreglo a la cual se ajusta a derecho la negativa del Registro Civil para autorizar la celebración de matrimonios en Chile de extranjeros cuya situación migratoria es irregular, y aquella según la cual dicha negativa no se ajusta a derecho.

\section{Planteamiento que refrenda la negativa del Registro Civil}

De acuerdo con esta postura, la negativa para autorizar la celebración de matrimonios en Chile de extranjeros que no puedan probar su residencia legal en el país resulta válida. ${ }^{27}$

Los argumentos en los que se funda esta postura, que también se encuentran en los votos disidentes de los fallos que han sostenido la postura contraria, han sido básicamente dos.

a) Se señala que conforme a lo establecido en los artículos 76 de la Ley de Extranjería y 5 del Reglamento de Extranjería, el Registro Civil se encuentra en la obligación legal de denegar la solicitud de celebrar matrimonio en Chile al extranjero que permanezca irregularmente en el

\footnotetext{
${ }^{27}$ Corte Suprema, 6 de octubre de 2016, Rol N44.989-16; Corte Suprema, 6 de octubre de 2016, Rol $\mathrm{N}^{\circ}$ 44.965-16; Corte Suprema, 6 de octubre de 2016, Rol N43.367-16, Corte Suprema, 10 de enero de 2017, Rol N92.948-16; Corte Suprema, 7 de agosto de 2017, Rol №19.018-17; Corte Suprema, 5 de septiembre de 2017, Rol N²8.014-17; Corte Suprema, 7 de agosto de 2017, Rol N¹8.206-2017; Corte Suprema, 2 de noviembre de 2017, Rol N³7.806-2017; Corte Suprema, 18 de diciembre de 2017, Rol N³8.750-2017; Corte Suprema, 29 de diciembre de 2017, Rol N³6.176-17; Corte Suprema, 11 de enero de 2018, Rol N41.917-2017; Corte Suprema, 6 de agosto de 2018, Rol N³.642-2018; Corte Suprema, 6 de agosto de 2018, Rol 4.170-2018; Corte Suprema, 6 de septiembre de 2018, Rol $\mathrm{N}^{\circ}$ 15.230-18; Corte Suprema, 8 de octubre de 2018, Rol Nº6.260-2018.
} 
país, al tiempo que las mismas normas determinan que sí se podrá acceder a dicha celebración en el caso de extranjeros que satisfacen el requisito de residir legalmente en Chile.

b) Se añade que tratándose de extranjeros que no pueden probar su permanencia legal en Chile, la negativa para autorizarlos a celebrar matrimonio en Chile no resulta ni ilegal, en razón de lo ya dicho, ni arbitraria, porque la negativa no se funda en su condición de extranjeros, sino que en su condición de extranjeros que residen ilegalmente en Chile. ${ }^{28}$

En cuanto a la forma en que los fallos se apoyan sobre las referidas normas legales para fundar el planteamiento que refrenda la negativa del Registro Civil, es posible constatar una evolución en la complejidad del argumento.

Así, en una primera etapa es notorio que los fallos que apoyan la tesis del Registro Civil se limitan a hacer suya la argumentación de dicho Servicio, la que podríamos denominar "argumentación legal tecnicista". La argumentación legal tecnicista, además de limitarse a invocar como fundamento las referidas normas legales, enfatiza que el artículo 76 de la Ley de Extranjería, aplicado al extranjero que quiere celebrar matrimonio en Chile, establece un requisito adicional a los requisitos establecidos en la Ley de Matrimonio Civil: que el extranjero pruebe su residencia legal en el país mediante la exhibición de la correspondiente cédula de identidad otorgada en conformidad a las normas de extranjería pertinentes, de manera que el extranjero que permanece irregularmente en Chile no podría contraer matrimonio en el país simplemente porque no está en condiciones de acreditar su residencia legal mediante la exhibición de la respectiva cédula de identidad.

Posteriormente, en una segunda etapa, el razonamiento se complejiza, configurándose el segundo argumento antes individualizado. Esta mayor sofisticación del argumento probablemente obedece a la necesidad de hacerse cargo de la contrargumentación respectiva: para los efectos de acreditar su identidad es suficiente para el extranjero exhibir su pasaporte vigente. Así,

\footnotetext{
${ }^{28}$ En el mismo sentido, se precisa que los recurrentesno ejercieron su derecho de reclamar la inaplicabilidad por inconstitucionalidad de las normas de extranjería supuestamente discriminatorias, agregándose que no se trata de que el extranjero carezca de CI, cuestión que sería meramente formal. Aquí hay incumplimiento de un requisito de fondo fijado por la ley migratoria nacional que los jueces están obligados a aplicar. El hecho del ingreso clandestino del recurrente a Chile por un paso no habilitado incluso está tipificado como delito en dicha ley.
} 
en esta segunda etapa se pasa a sostener que la negativa del Registro Civil no es ilegal, ni arbitraria. Se señala que no es ilegal porque la norma del artículo 76 de la Ley de Extranjería, plenamente vigente, impone al Oficial Civil la obligación de exigir al extranjero que desea contraer matrimonio que pruebe su residencia legal en Chile. Y se señala que no es arbitraria porque no se niega la posibilidad de contraer matrimonio a todo extranjero, sino que solo a aquellos extranjeros que se encuentren ilegalmente en Chile, agregándose que dicha negativa procede en contra de todo extranjero que se encuentre en la misma situación de ilegalidad en Chile, generalidad que dejaría en evidencia que no se trata de una negativa discriminatoria. A mayor abundamiento, se indica que, por el contrario, se concede la posibilidad de contraer matrimonio a todo extranjero que se encuentre en la situación inversa, esto es, que esté condiciones de probar que reside legalmente en Chile.

3. El planteamiento que sostiene que no se ajusta a derecho la negativa para autorizar la celebración de matrimonios en Chile de extranjeros que no puedan probar su residencia legal en el país

El análisis de los fallos que ilustran este planteamiento, ${ }^{29}$ nos permite identificar cuatro argumentos fundamentales, argumentos que también se encuentran en los votos disidentes de los fallos que refrendan la postura del Registro Civil.

a) Se concibe la existencia del derecho a contraer matrimonio como un derecho fundamental de toda persona, a pesar de no estar expresamente declarado como tal en el artículo 19 de la CPR. La consideración de un derecho a contraer matrimonio, el cual se concibe como un derecho fundamental, se funda en los artículos 1 y 5 de la CPR y en el artículo 17 de la $\mathrm{CADH} .{ }^{30}$

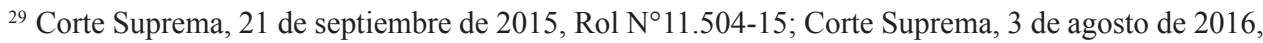
Rol N¹9.634-16; Corte Suprema, 30 de agosto de 2016, Rol N³5.236-16; Corte Suprema, 30 de agosto de 2016, Rol 35.237-16; Corte Suprema, 4 de mayo de 2017, Rol N4.732- 17; Corte Suprema, 27 de junio de 2017, Rol N¹0.224-17; Corte Suprema, 6 de julio de 2017, Rol N5.067-17; Corte Suprema, 6 de julio de 2017, Rol 5.073-17; Corte Suprema, 3 de octubre de 2017, Rol N³0.221-2017; Corte Suprema, 18 de abril de 2018, Rol 6.111-2018; Corte Suprema, 10 de diciembre de 2018, Rol $\mathrm{N}^{\circ}$ 20.502-2018; Corte Suprema, 12 de julio de 2018, Rol N¹2.130-2018; Corte de Apelaciones de Santiago, 3 de septiembre de 2018, Rol N51.053-2018; Corte Suprema, 26 de noviembre de 2018, Rol N6.109-2018.

${ }^{30}$ De allí que se considere a los fallos favorables a esta postura como emblemáticos de un reconocimiento
} 
b) Luego de distinguir expresamente entre dos dimensiones de análisis de una norma legal a la luz de la CPR, esto es, la dimensión de derogación de una norma legal por una norma constitucional posterior y la dimensión de inconstitucionalidad de una norma legal, se afirma que los tribunales ordinarios tienen competencia en la primera de las referidas dimensiones de análisis, esto es, tienen competencia para analizar la vigencia de una norma legal a la luz de la Constitución y para concluir, en virtud de dicho análisis, que tal norma legal ha sido derogada tácitamente por una norma constitucional posterior. De esta manera, y en relación con la norma del artículo 76 de la Ley de Extranjería, analizada a la luz de normas constitucionales posteriores, es dable concluir que existe contradicción o falta de armonía entre aquella y estas (el tantas veces citado artículo 76 permitiría exigir como requisito para contraer matrimonio en Chile la prueba de la residencia legal en el país, lo que resulta incompatible con la consideración del derecho a contraer matrimonio como un derecho fundamental que emana de la naturaleza humana, derecho que, por tal razón, no puede estar sometido a exigencias como las que establece el mencionado artículo 76). Tal antinomia, junto con la consideración del derecho de igualdad ante la ley, conduce a concluir que la norma del artículo 76 de la Ley de Extranjería, en cuanto permitiría desconocer el derecho de un extranjero que habite en Chile a contraer matrimonio, norma injustificadamente discriminatoria, ha sido derogada tácitamente por normas constitucionales posteriores, o, al menos, conduce a la necesidad de interpretar el referido artículo 76 en una forma que sea compatible con las normas constitucionales (lo que lleva a entender que no se puede exigir a un extranjero el probar su residencia legal en Chile como requisito para contraer matrimonio).

c) Se sostiene que la LMC establece un sistema cerrado y completo de normas que regulan los requisitos para contraer matrimonio en Chile (artículo 4 en relación con los artículos 9 a 16, todos de la LMC), normas legales que, en virtud del principio de la especialidad, consagrado en el artículo 1 de la LMC, deben primar sobre la norma del artículo 76 de la Ley de Extranjería. En otras palabras, se sostiene que son las normas de la LMC recién referidas las únicas llamadas a establecer los requisitos para contraer

jurisdiccional del ejercicio igualitario de derechos en Chile entre nacionales y extranjeros. MonTECinOs, Rodolfo, "El derecho a contraer matrimonio de los extranjeros (sentencia Corte Suprema, 18 de abril de 2018, rol N 6111-2018)", Estudios Constitucionales, 2019, Año 17 N 1, p. 445. 
matrimonio, en conformidad a lo dispuesto en el artículo 1 de la misma LMC. ${ }^{31}$

d) Se sostiene que como el derecho a contraer matrimonio es un derecho esencial de la naturaleza humana, la norma del artículo 76 de la Ley de Extranjería debe ser interpretada restrictivamente, única interpretación que salvaguarda las obligaciones internacionales contraídas por el Estado de Chile (artículo 17 de la CADH).

4. Algunas puntualizaciones respecto de los argumentos desplegados en el debate judicial.

Por nuestra parte, tres son las puntualizaciones que nos parece pertinente formular con respecto a los argumentos desplegados en el debate judicial.

En primer lugar, cabe destacar que más allá de que la CS refrende o rechace la negativa del Registro Civil, este debate es una clara evidencia de la constitucionalización del derecho de familia y de su efecto propio consistente en la incorporación al ordenamiento jurídico interno de derechos fundamentales consagrados en tratados internacionales. En este sentido, entonces, el reconocimiento del derecho a contraer matrimonio del art. 17 de la CADH, vía art. 5 inc. $2^{\circ}$ de la CPR, es manifestación estricta del fenómeno de constitucionalización del derecho de familia chileno.

Ello conlleva un efecto importantísimo: además de la incorporación de un derecho fundamental no enumerado expresamente en la CPR al catálogo de derechos protegidos, se le otorga la garantía de la acción de protección. Lo dice la Corte Suprema: "se colige la existencia de derechos fundamentales que no necesariamente se encuentran expresamente declarados en el texto fundamental, y, entre ellos, está el derecho a contraer matrimonio". 32

En segundo término, los fallos divididos dan cuenta del conflicto latente entre la CS y el Tribunal Constitucional (en adelante, TC) sobre el ejercicio del control de constitucionalidad de las normas.

A partir de la reforma constitucional del año 2005 que consagró

\footnotetext{
${ }^{31}$ En el mismo sentido se señala que la Contraloría dictaminó que la exigencia de residencia legal en cuestión no es aplicable a los extranjeros que se encuentran irregularmente en nuestro país para inscribir el nacimiento de sus hijos. Por consiguiente, debe aplicarse al ejercicio del derecho al matrimonio el mismo razonamiento.

${ }^{32}$ Considerando $5^{\circ}$, sentencia Corte Suprema, 30 de agosto de 2016, Rol N³5.236-16.
} 
en esta materia el control concentrado del TC con el objeto de lograr una unidad interpretativa y una aplicación uniforme de la constitución, ${ }^{33}$ se aprecia una tensión entre, por un lado, la facultad de dicho tribunal para decretar la incompatibilidad de una norma legal con la constitución, sea por vía de requerimiento de inaplicabilidad por inconstitucionalidad o por vía de acción de inconstitucionalidad (art. $92 \mathrm{n}^{\circ} 6$ y 7 de la CPR), y la facultad de la CS de fijar el derecho aplicable al caso concreto. Esto último aparece, especialmente, en la resolución de los conflictos en que un ciudadano reclama ante el máximo tribunal el amparo de un derecho fundamental a través de un recurso de amparo o de protección, puesto que en ellos no solo se trata de garantizar la supremacía de la norma constitucional frente a otra norma o acto, sino "primariamente - o así debiera ser- la de amparar la plena vigencia y aplicación de un derecho fundamental de una persona, que la Constitución se encarga de proteger y garantizar". ${ }^{34} \mathrm{Si}$ en esta tarea la norma vulnera dicho derecho fundamental, entonces, la cuestión es si al declararla derogada, la CS estaría invadiendo la esfera de control reservada al TC.

La CS ha afirmado su competencia para pronunciarse respecto de la eventual derogación tácita de preceptos legales preconstitucionales, esto es, precepto legales que entran en conflicto con una Constitución posterior o con una posterior reforma de la Constitución vigente, mientras que el TC ha proclamado su competencia exclusiva para fallar sobre la compatibilidad de cualquier precepto legal con la Constitución vigente, sea dicho precepto legal anterior o posterior a la Constitución o a su reforma.

Esta disputa divide a la doctrina especializada en el mismo sentido que lo está la jurisprudencia en estudio: mientras unos consideran que la contradictoriedad de preceptos legales preconstitucionales con la Constitución constituye un caso de inconstitucionalidad sobrevenida, y no de derogación, atribuyendo su conocimiento únicamente al TC, ${ }^{35}$ otros estiman que corresponde a los tribunales del fondo pronunciar su derogación. ${ }^{36}$

\footnotetext{
${ }^{33}$ GómEz, Gastón, Las sentencias del tribunal constitucional y sus efectos sobre la jurisdicción común, Ediciones Universidad Diego Portales, Santiago, 2013, lera edición, p. 17.

${ }^{34}$ Ferrada, Juan Carlos, "Los derechos fundamentales y el control constitucional”, Revista de Derecho (Valdivia), 2004, Vol. XVII, p. 123.

${ }^{35}$ ZÚÑIGA, Francisco, "Control difuso de normas: Comentario a la sentencia Rol No35236-2016 de la Corte Suprema de 30 de agosto de 2016”, Estudios Constitucionales, 2017, Año 15, No 1, p. 429 y 432.

${ }^{36}$ Esta disputa doctrinal está resumida en Henríquez Viñas, Miriam, “¿Derogación tácita o inaplicabilidad de preceptos legales preconstitucionales?", Estudios Constitucionales, Año 15, Nº1,
} 
Detrás de esta tensión entre los dos tribunales, existe, sin embargo, un sustrato común no controvertido: ambos parten de la base que la CPR constituye una fuente normativa de aplicación directa. La CS declara estar directamente vinculada por la norma constitucional (el derecho a contraer matrimonio, vía art. 5 inc. $2^{\circ}$ de la CPR) y, por consiguiente, obligada a determinar que como norma jurídica vigente y aplicable al caso concreto, ha drogado tácitamente el precepto legal preconstitucional.

Por su parte, en la lógica de la postura del TC, este admite que la CS está directamente vinculada a la CPR, a consecuencia de lo cual también resulta obligada a objetar la constitucionalidad de cualquier precepto legal (anterior o posterior) a través de un requerimiento de inaplicabilidad por inconstitucionalidad ante él.

Queda abierta la pregunta de por qué la CS, para evitar esta disputa con el TC no ha conducido su argumentación por la vía del control de convencionalidad. A través de él, podría lograr el mismo resultado (declarar que el art. 76 de la Ley de Extranjería está derogado por el art. $17 \mathrm{CADH}$ ), sin que pudiera oponérsele una extralimitación de facultades.

En tercer lugar, es interesante referirse a la forma en que las posturas en debate, particularmente aquella que apoya la negativa del Registro Civil, se aproximan a las normas legales relevantes, con prescindencia de razonamientos relativos a normas constitucionales o de tratados internacionales con rango constitucional. En efecto, es posible identificar en ambas posturas argumentos que dicen relación exclusivamente con cuestiones de interpretación legal.

Así, y en lo que concierne a la postura que refrenda la negativa del Registro Civil, es de destacar la completa omisión de un análisis conceptual del ius connubii, esto es, del derecho a contraer matrimonio y de su consideración como derecho fundamental. Esta omisión fluye, a su vez, de la ausencia de consideración de las normas constitucionales y de las normas de tratados internacionales que tienen rango constitucional, a partir de las cuales se puede fundar la existencia del ius connubii como un derecho fundamental de toda persona. Hay una referencia exclusiva a las normas de los artículos 76 de la Ley de Extranjería y 5 del Reglamento de Extranjería, sin entrar a analizar cómo deben entenderse dichas normas a la luz del sistema de requisitos para contraer matrimonio que establece la LMC. $^{37}$

2017, pp. $307-328$.

${ }^{37}$ En el mejor de los casos, se señala que no se ha citado norma legal interna, ni de tratados 
Ahora, no nos deja de llamar la atención que, no obstante la ausencia de consideración de eventuales normas constitucionales, los fallos en los que ha predominado la postura que refrenda la negativa del Registro Civil, parecen reconocer tácitamente que la norma del artículo 76 de la Ley de Extranjería (norma fundamental en la argumentación de dicha postura) podría ser objeto de reproche constitucional. En efecto, solo así se puede entender la constante precisión, en los respectivos fallos, de que no constaba que se hubiera pedido ante el Tribunal Constitucional la inaplicabilidad por inconstitucionalidad del artículo 76 de la Ley de Extranjería. ${ }^{38}$

De esta manera, la argumentación que refrenda la negativa del Registro Civil, en lo esencial, gira en torno al sentido y alcance de la norma del artículo 76 de la Ley de Extranjería en relación con el artículo 5 del Reglamento de Extranjería. Sin embargo, incluso la sola consideración de la referida norma legal no impide argumentar en sentido contrario a tal postura. En efecto, creemos que es posible formular a lo menos tres observaciones en relación con la forma en que la postura que refrenda la negativa del Registro Civil se aproxima a la norma del artículo 76 de la Ley de Extranjería.

a) Primeramente, la postura que refrenda la negativa del Registro Civil parece no tomar en cuenta que el artículo 76 de la Ley de Extranjería hace una separación expresa: el precepto exige que los extranjeros previamente comprueben su residencia legal en el país y, además, que estén autorizados o habilitados para realizar el correspondiente acto o contrato. Es decir, el propio precepto concibe la prueba de la residencia legal en el país como un elemento que no forma parte de las condiciones para celebrar el respectivo acto jurídico. Así, es dable entender que la exigencia de prueba de la residencia legal es solo una medida de política legislativa para fiscalizar el cumplimiento de las normas de extranjería, y no un requisito adicional para celebrar el respectivo acto jurídico (al respecto, es notorio el contraste, por ejemplo, con el artículo 77 de la Ley de Extranjería, norma que solo habla de

internacionales, que, destacando la relevancia de la familia y del matrimonio, permita a los servicios del Estado soslayar su normativa interna aplicable al caso. Véase en este sentido, Corte Suprema, 29 de diciembre de 2017, Rol N³6.176-2017.

${ }^{38}$ Normas de la referida Ley de Extranjería ya han sido sometidas al control de constitucionalidad del TC, con resultados diversos. En este sentido, puede revisarse el trabajo de: GALDÁmEz, Liliana, "Comentario jurisprudencial sobre la sentencia del Tribunal Constitucional Rol No 2273-12-INA sobre inaplicabilidad de normas del D.L. No 10.094 que establece normas sobre los extranjeros en Chile y las matizaciones de la Rol No 2257-12-INA”, Estudios Constitucionales, 2013, Año 11 № 2, pp. 769-782. 
la residencia legal en el país). ${ }^{39}$ En este sentido, lo dicho aquí refuerza el que hemos identificado como tercer argumento del planteamiento que rechaza la negativa del Registro Civil, antes señalado.

b) La postura que refrenda la negativa del Registro Civil olvida una norma legal relevante: el artículo $57 \mathrm{CC}$, norma que dispone que la ley no reconoce diferencias entre el chileno y el extranjero en cuanto a la adquisición y goce de los derechos civiles que regla el propio CC. No se puede pretender aplicar la norma del artículo 76 de la Ley de Extranjería sin consideración alguna de otra norma de igual rango, como lo es el artículo 57 del CC. Se deben considerar ambas normas, en una manera integrada y coherente.

c) Abona lo dicho en el punto anterior, el que el CC, cuando quiere establecer una diferencia expresa entre el extranjero que reside legalmente y el que no tiene residencia legal, lo señala expresamente. Son ilustrativas en este sentido las normas del número 10 del artículo 1012 del CC y la del número 1 del artículo 1028 del CC. ${ }^{40}$

Es claro que las tres observaciones recién referidas refuerzan la postura que rechaza la negativa del Registro Civil incluso prescindiendo de toda consideración de normas constitucionales, es decir, situándose en el mismo plano argumentativo que despliega la postura que refrenda la negativa del Registro Civil, la que, como hemos señalado, omite cualquier consideración de normas constitucionales.

Por cierto, dicho reforzamiento viene a complementar el argumento exclusivamente legal que formula la postura que rechaza la negativa del Registro Civil, argumento que, como se ha dicho, plantea que la LMC establece un sistema cerrado y completo de normas que regulan los requisitos para contraer matrimonio en Chile (artículo 4 en relación con los artículos

\footnotetext{
${ }^{39}$ El artículo 77 dispone:

"Los propietarios, administradores, gerentes, encargados o responsables de hoteles, residenciales o casas de hospedaje que alojen a extranjeros, como asimismo, los propietarios o arrendadores que convengan o contraten con ellos arrendamiento, deberán exigirles previamente que acrediten su residencia legal en el país.

El incumplimiento de esta obligación será sancionado con multa de uno a veinte sueldos vitales.

Los particulares que dieren alojamiento a extranjeros en situación irregular serán sancionados con la multa de 1 a 10 sueldos vitales".

${ }^{40}$ Conforme al número 10 del artículo 1012 CC no podrán ser testigos en un testamento solemne, otorgado en Chile, los extranjeros no domiciliados en el país. Por su parte, conforme al número 1 del artículo $1028 \mathrm{CC}$, solo podrán testar en el extranjero conforme a la ley chilena un chileno, o un extranjero que tenga domicilio en Chile.
} 
9 a 16, todos de la LMC), normas legales que, en virtud del principio de la especialidad, consagrado en el artículo 1 de la LMC, deben primar sobre la norma del artículo 76 de la Ley de Extranjería. Con relación a este argumento legal cabe mencionar que se trata de una justificación conocida para la jurisprudencia nacional en materia de derecho matrimonial. Así, por ejemplo, en la discusión acerca de la procedencia o improcedencia de la indemnización de perjuicios por infracción de deberes matrimoniales entre los cónyuges, los fallos de los tribunales superiores han invocado la especialidad del derecho de familia para desechar la aplicación del régimen de responsabilidad civil frente a estos hechos dañosos. Aludiendo al fundamento y contenido propios de las relaciones de familia en comparación con el derecho civil patrimonial, han privilegiado la aplicación de la consecuencia jurídica prevista específica y expresamente por el estatuto matrimonial para dichas infracciones, esto es, el divorcio por sobre la indemnización de los perjuicios. ${ }^{41}$

En suma, considerando únicamente la interpretación de las normas legales relevantes, pareciera que la postura que rechaza la negativa del Registro Civil muestra mayores fortalezas que la postura que refrenda dicha negativa.

Finalmente, respecto de los argumentos desplegados en el debate judicial, cabe destacar la ausencia en él de toda consideración relativa al problema que plantean los matrimonios simulados celebrados por extranjeros en situación irregular con el objeto de eludir la aplicación de las normas migratorias pertinentes. En particular, no se observa un esfuerzo por establecer que en cualquier análisis del ius connubii de los extranjeros en situación irregular, se hace necesario ocuparse de aquellas hipótesis en que un extranjero se vale de un matrimonio con la única finalidad de burlar o eludir las normas migratorias pertinentes.

La referida cuestión ha sido analizada por algunos autores ${ }^{42}$. Conforme a dicho análisis se hace necesario distinguir dos situaciones: la de dos extranjeros en situación irregular que pretenden contraer o contraen

\footnotetext{
${ }^{41}$ En este sentido puede revisarse la sentencia de la CA de Santiago, de 10 de noviembre de 2009, Rol N 7738-07, confirmada por fallo de la Corte Suprema, de 3 de junio de 2012, Rol N²63-10. Un análisis acabado del argumento de la especialidad, así como de los demás fundamentos de esta posición jurisprudencial, puede verse en TAPIA, Mauricio, "Divorcio y responsabilidad civil en el Derecho chileno", Revista de Derecho Universidad de Concepción, 2016, n² 239, enero-junio, pp. 154-156.

42 Barrientos, Javier, Derecho de las Personas. El Derecho Matrimonial, Thomson Reuters/ LegalPublishing Chile, Santiago, 2011, pp. 298-302; MondACA, Alexis, "Un supuesto de ausencia de consentimiento matrimonial: los mal denominados 'matrimonios de conveniencia' o 'matrimonios de complacencia'”, Revista Ius et Praxis, 2018, año $24 \mathrm{~N}^{\circ}$ 1, pp. 623-658.
} 
matrimonio en Chile y la del extranjero (a) en situación irregular que pretende contraer o contrae matrimonio en Chile con un (a) chileno (a).

La primera de las referidas situaciones no se presta para simular un matrimonio con el fin de burlar o eludir las normas migratorias, por cuanto un matrimonio entre extranjeros en situación irregular no conduce a la obtención de beneficios migratorios para ninguno de los contrayentes. Por ello, en relación con esta situación cabe desplegar únicamente las consideraciones del debate judicial relativas al derecho a contraer matrimonio de los extranjeros en situación irregular.

Es la segunda de las situaciones la que puede ser funcional a una simulación del matrimonio para obtener beneficios migratorios. En efecto, esta situación posibilita que tenga lugar la hipótesis de un(a) extranjero(a) en situación irregular que pretende contraer o contrae matrimonio en Chile con un(a) chileno(a) con la única finalidad de obtener un beneficio migratorio (fundamentalmente, mejorar su situación migratoria, regularizando una condición que era irregular). Ahora, en relación con esta situación es posible distinguir dos posibilidades.

La primera posibilidad es la de un(a) extranjero(a) en situación irregular que, en concierto con un(a) chileno(a), simula un matrimonio en Chile con la finalidad de regularizar su situación migratoria. Se habla en este caso de simulación total concertada o bilateral. Al respecto se plantea que dicha simulación da cuenta de la ausencia o inexistencia de consentimiento matrimonial (no hay consentimiento dirigido a formar la comunidad de vida que implica el matrimonio), por lo que dicha simulación se traduce en la inexistencia del matrimonio. ${ }^{43}$

La segunda posibilidad es la de un(a) extranjero(a) en situación irregular que unilateralmente simula un consentimiento matrimonial para contraer matrimonio con un(a) chileno(a), quien, por su parte, manifiesta una verdadera voluntad matrimonial, ignorando la simulación del (la) extranjero(a). Se habla en este caso de simulación total unilateral. Con respecto a la sanción de esta hipótesis la cuestión es debatida. Por una parte, se plantea que en este caso la sanción también sería la inexistencia del matrimonio, mientras que según otra postura la sanción pertinente sería la nulidad del matrimonio. ${ }^{44}$

\footnotetext{
${ }^{43}$ Barrientos, cit. (n. 42), pp. 300-305; Mondaca, cit. (n. 42), p. 647 y ss.

${ }^{44}$ MondaCA, cit. (n. 42), p. 651, sostiene que en el caso de la simulación unilateral la sanción también es la inexistencia porque, en definitiva, no hay consentimiento matrimonial: la voluntad del contrayente
} 
¿Por qué en el debate judicial acerca de los extranjeros en situación irregular y el ius connubii no se toca la cuestión relativa a la eventual simulación del matrimonio con la finalidad de burlar las normas migratorias? Estimamos que la explicación hay que buscarla en el hecho de que la cuestión de la simulación se planteará muy probablemente después de la celebración del matrimonio (solo después del matrimonio se contará con elementos que permitan establecer cuál fue la real intención de los contrayentes), mientras que el debate judicial que hemos analizado tiene lugar antes de la celebración del matrimonio (se discute si el extranjero en situación irregular tiene o no derecho a contraer matrimonio en Chile).

A partir de lo dicho podríamos agregar que sería inadecuado introducir en este debate (el relativo al derecho a contraer matrimonio de los extranjeros en situación irregular) la cuestión de la eventual simulación del matrimonio. En concreto, pensamos que no sería correcto esgrimir como argumento para refrendar la negativa del Registro Civil el aludir a la necesidad de evitar la celebración de matrimonios simulados para burlar las normas migratorias. No sería correcto por dos razones. En primer lugar, porque la cuestión de la eventual simulación solo puede configurarse en una hipótesis (la del extranjero o extranjera en situación irregular que simula un matrimonio en Chile con una chilena o con un chileno, con la finalidad de burlar normas migratorias), no planteándose en otras hipótesis de matrimonios de extranjeros en situación irregular (matrimonio en Chile entre extranjeros en situación irregular, o entre extranjeros, uno en situación irregular y el otro en situación regular). Y, en segundo lugar, porque la cuestión de la eventual simulación se plantea y se puede detectar después del matrimonio, mientras que el debate relativo al derecho a contraer matrimonio en Chile de los extranjeros en situación irregular se plantea necesariamente antes.

que manifestó realmente una voluntad matrimonial no coincide con la voluntad del otro contrayente, quien simplemente simuló una voluntad matrimonial. En cambio, BARRIENTOS, cit. (n. 42), pp. 305-306, plantea que la sanción sería la nulidad por error padecido por el contrayente que realmente manifestó una voluntad matrimonial, en conformidad al artículo $8 \mathrm{~N}^{\circ} 2$ de la Ley de Matrimonio Civil. 


\section{CONCLUSIONES}

1. El derecho de toda persona a contraer matrimonio o ius connubii ha cobrado actualidad en nuestro país a propósito de su ejercicio por parte de personas extranjeras que no cuentan con la autorización legal de permanecer en Chile. Sin embargo, a la luz del fenómeno de constitucionalización del derecho de familia no debiera llamar la atención que un derecho no contemplado expresamente por la CPR reciba tutela judicial a través de la acción constitucional de protección.

2. La jurisprudencia dividida de la CS pronunciada en sede de recursos de protección interpuestos por extranjeros cuya situación migratoria es irregular y que desean contraer matrimonio en Chile, demuestra la necesidad de ajustar el estatuto legal de inmigración a los estándares de derechos humanos contenidos en los tratados internacionales ratificados por nuestro país.

3. Existe coherencia en la argumentación que sustenta a las dos posturas en juego: cada una de ellas conduce lógicamente a la conclusión que se busca justificar, ya sea la legalidad de la negativa del Registro Civil a permitir el matrimonio de los inmigrantes en cuestión o su ilegalidad. Sin perjuicio de lo dicho, a la luz de la sola consideración de las normas legales relevantes, esto es, con prescindencia de normas constitucionales o de tratados internacionales con rango constitucional, la postura que rechaza la negativa del Registro Civil se revela con mayores fortalezas.

4. En el estado actual de la normativa de extranjería (normas de la década del 70 y 80 del siglo pasado, algunas contenidas en un Decreto Ley y otras que consisten, incluso, en normas de rango infralegal), nos inclinamos por la improcedencia de la actuación administrativa desde que impide el ejercicio del derecho a contraer matrimonio reconocido a todas las personas. Sin perjuicio de ello, no parece descabellado imaginar un estatuto legal de inmigración que contemplara algún requisito general que, en armonía con la LMC, regulara racionalmente el ejercicio de tal derecho por parte de las personas extranjeras con situación de migración irregular (el diseño de una normativa compatible escapa al objetivo de este trabajo). 


\section{BIBLIOGRAFÍA}

\section{a) Doctrina}

AcuÑA, Sara "El derecho a contraer matrimonio y el derecho a formar una familia en los textos internacionales de derechos humanos y en la Constitución española de 1978". En: MorÁn, G. (Ed.), Cuestiones actuales de derecho comparado, Ediciones Universidade da Coruña, España, 2003, pp. 225-234.

Adroher, Salomé, "El derecho a contraer matrimonio en la emigración", Migraciones, 1996, nº, pp. 107-131.

AldunAte Eduardo, "El derecho esencial a contraer matrimonio" en: VIDAL, Álvaro (ed.), El nuevo derecho chileno del matrimonio, Editorial Jurídica, Santiago, 2006.

Badilla, Ana Elena, El derecho a constitución y la protección de la familia en la normativa y la jurisprudencia del Sistema Interamericano de Derechos Humanos, Editorial Porvenir, San José, 1996.

Barrientos, Javier, Derecho de las Personas. El Derecho Matrimonial, Thomson Reuters/LegalPublishing Chile, Santiago, 2011.

BArrientos, Javier; Novales, Aranzazu, Nuevo derecho matrimonial chileno, Lexis Nexis, Santiago, 2004.

Beloff, Mary, "Art. 17. Protección a la Familia”, en: Steiner, C.; Fuchs, M. (Eds.), Convención Americana de Derechos Humanos. Comentarios. Konrad Adenauer Stiftung, Bogotá, segunda edición, 2019, pp. 477-518.

Cabanillas, Antonio, "Derecho a la Constitución de la familia y a su protección”, Revista Electrónica Iberoamericana, 2019, vol. 13, ed. especial.

Domínguez, Ramón, "Aspectos de la constitucionalización del Derecho Civil chileno", Revista de Derecho y Jurisprudencia, 1996, Tomo XCIII, Nro. 3, pp. $107-137$.

EsPejo, Nicolás; LATHRoP, Fabiola, "Hacia la constitucionalización del derecho de familia en Latinoamérica", Revista de derecho privado Universidad del Externado, 2020, n 38, pp. 89 -116.

FERnÁNDEZ, Francisco, El sistema constitucional español, Editorial Dykinson, Madrid, 1992.

FERradA, Juan Carlos, "Los derechos fundamentales y el control constitucional”, Revista de Derecho (Valdivia), 2004, Vol. XVII, pp.113-137.

GALdÁMEz, Liliana, "Comentario jurisprudencial sobre la sentencia del Tribunal Constitucional Rol N²273-12-INA sobre inaplicabilidad de normas del D.L. $\mathrm{N}^{\mathrm{o}} 10.094$ que establece normas sobre los extranjeros en Chile y las matizaciones de la Rol N²257-12-INA", Estudios Constitucionales, 2013, Año 11 No2, pp. 769 - 782.

GómEz, Gastón, Las sentencias del tribunal constitucional y sus efectos sobre la jurisdicción común, Santiago, Ediciones Universidad Diego Portales, 
Santiago, 2013.

Henríquez, Miriam, ¿Derogación tácita o inaplicabilidad de preceptos legales preconstitucionales?", Estudios Constitucionales, 2017, Año 15 № 1, pp. 312-315.

LATHrop, Fabiola, "Constitucionalización y Jurisprudencia Constitucional en el Derecho de Familia chileno", Estudios Constitucionales, 2017, Año 15 n ${ }^{\circ} 1$, $329-372$.

Lepín, Cristián, Derecho familiar chileno, Thomson Reuters, Santiago, 2017.

Molina, Carlos; Carrillo, Yudi, "El matrimonio de parejas del mismo sexo y la Corte Constitucional de Colombia", Revista de Derecho (Valdivia), 2018, vol. XXXI n 1, pp. 79-103.

MondACA, Alexis, "Un supuesto de ausencia de consentimiento matrimonial: los mal denominados 'matrimonios de conveniencia' o 'matrimonios de complacencia", Revista Ius et Praxis, 2018, año $24 \mathrm{~N}^{\circ} 1$.

Montecinos, Rodolfo, "El derecho a contraer matrimonio de los extranjeros (sentencia Corte Suprema, 18 de abril de 2018, rol N ${ }^{\circ}$ 6111-2018)", Estudios Constitucionales, 2019, Año 17 No 1, pp. 443-458.

Roca I Trias, Encarna, Familia y cambio social (de la “casa” a la persona), Madrid, Civitas, 1999.

Rodríguez, María Sara, Manual de Derecho de Familia, Editorial Jurídica, Santiago, 2017.

TAPIA, Mauricio, "Divorcio y responsabilidad civil en el Derecho chileno", Revista de Derecho Universidad de Concepción, 2016, n² 239, pp. 139-198.

Turner, Susan, "Familia, matrimonio y derechos. El derecho a contraer matrimonio", en: Elorriaga, F. (Ed.), Estudios de Derecho Civil VII., Thomson Reuters, Santiago, 2012, pp. 29-39.

ZúÑIgA, Yanira; Turner, Susan, "Sistematización comparativa de la regulación de la familia en las constituciones latinoamericanas", Revista de Derecho Universidad Católica del Norte, 2013, Año 20 n 2, pp. 269-301.

ZúÑIgA UrbinA, Francisco, "Control difuso de normas: Comentario a la sentencia Rol N $35236-2016$ de la Corte Suprema de 30 de agosto de 2016”, Estudios Constitucionales, 2017, Año 15 No 1, pp. 425 - 432.

\section{b) Jurisprudencia}

Corte Suprema, 21 de septiembre de 2015, Rol N ${ }^{\circ}$ 11.504-15 (confirma sentencia de Corte de Apelaciones de Santiago de 7 de agosto de 2005, Rol $\mathrm{N}^{\circ}$ 53381-15).

Corte Suprema, 3 de agosto de 2016, Rol N¹9.634-16 (confirma sentencia de Corte de Apelaciones de Santiago, 17 de marzo de 2017, Rol N ${ }^{\circ}$ 13877-16).

Corte Suprema, 30 de agosto de 2016, Rol N³5.236-16 (revoca sentencia de Corte de Apelaciones de Santiago, 27 de mayo de 2016, Rol № 34170-16). 
Corte Suprema, 30 de agosto de 2016, Rol № 35.237-16 (revoca sentencia de Corte de Apelaciones de Santiago de 27 de mayo de 2016, Rol N 31513-2016). Corte Suprema, 6 de octubre de 2016, Rol N 44.989-16 (confirma sentencia de Corte de Apelaciones de Santiago, 7 de junio de 2016, Rol No 40778-2016).

Corte Suprema, 6 de octubre de 2016, Rol N 44.965-16 (confirma sentencia de Corte de Apelaciones de Santiago, 6 de julio de 2016, Rol N 19576-2016).

Corte Suprema, 6 de octubre de 2016, Rol N 43.367-16 (confirma sentencia de Corte de Apelaciones de Santiago, 23 de junio de 2016, Rol № 33932-2016).

Corte Suprema, 10 de enero de 2017, Rol No 92.948-16 (confirma sentencia de Corte de Apelaciones de Santiago, 3 de noviembre de 2016, Rol N ${ }^{\circ} 112522-$ 2016).

Corte Suprema, 4 de mayo de 2017, Rol N 4732- 17 (confirma sentencia de Corte de Apelaciones de Santiago, 17 de enero de 2017, Rol N 124756-2016).

Corte Suprema, 27 de junio de 2017, Rol N ${ }^{\circ}$ 10.224-17 (revoca sentencia de la Corte de Apelaciones de Santiago, 15 de octubre de 2016, Rol N ${ }^{\circ} 114667-2016$ ).

Corte Suprema, 6 de julio de 2017, Rol N 5067-17 (revoca sentencia de la Corte de Apelaciones de Santiago, 30 de enero de 2017, Rol N ${ }^{\circ} 1560-2017$ ).

Corte Suprema, 6 de julio de 2017, Rol No 5073-17 (confirma sentencia de la Corte de Apelaciones de Santiago, 30 de enero de 2017, Rol N 1613-2017).

Corte Suprema, 7 de agosto de 2017, Rol N 19.018-17 (revoca sentencia de la Corte de Apelaciones de Santiago, 4 de abril de 2017, Rol N¹3932-2017).

Corte Suprema, 7 de agosto de 2017, Rol N 18.206-17 (confirma sentencia de la Corte de Apelaciones de Santiago, 21 de abril de 2017, Rol N ${ }^{\circ}$ 13725-2017).

Corte Suprema, 5 de septiembre de 2017, Rol N²8.014-17 (revoca sentencia de la Corte de Apelaciones de Santiago, 26 de mayo de 2017, Rol N²9835/2017).

Corte Suprema, 3 de octubre de 2017, Rol No 30.221-17 (confirma sentencia de Corte de Apelaciones de Temuco, 29 de mayo de 2017, Rol No 1705-2017).

Corte Suprema, 2 de noviembre de 2017, Rol N³7.806-17 (revoca sentencia de Corte de Apelaciones de Iquique, 14 de agosto de 2017, Rol N 564-2017).

Corte Suprema, 18 de diciembre de 2017, Rol N³8750- 17 (revoca sentencia de la Corte de Apelaciones de Santiago, 29 de agosto de 2017, Rol N 45662-2017).

Corte Suprema, 29 de diciembre de 2017, Rol N ${ }^{\circ}$ 36.176-17 (confirma sentencia de Corte de Apelaciones de Santiago, 18 de julio de 2017, Rol N ${ }^{\circ} 40.351-$ 2017).

Corte Suprema, 11 de enero de 2018, Rol N 41.917-17 (revoca sentencia de la Corte de Apelaciones de Santiago, 13 de octubre de 2017, Rol No 61207-2017).

Corte Suprema, 18 de abril de 2018, Rol N 6.111-18 (confirma sentencia de la Corte de Apelaciones de Santiago, 20 de marzo de 2018, Rol N 8159-2018).

Corte Suprema, 12 de julio de 2018, Rol No 12.130-18 (confirma sentencia de la Corte de Apelaciones de San Miguel, 15 de mayo de 2018, Rol N²339-2018).

Corte Suprema, 6 de agosto de 2018, Rol No 3.462-18 (revoca sentencia de 
Corte de Apelaciones de San Miguel, 16 de febrero de 2018, Rol N 539-2018).

Corte Suprema, 6 de agosto de 2018, Rol N 4.170-18 (revoca sentencia de Corte de Apelaciones de Concepción, 9 de febrero de 2018, Rol N 6697-2017).

Corte Suprema, 6 de septiembre de 2018, Rol No 15230-2018 (revoca sentencia de la Corte de Apelaciones de Santiago, 18 de junio de 2018, Rol $\mathrm{N}^{\circ}$ 35305-2018).

Corte Suprema, 8 de octubre de 2018, Rol № 6.260-18 (confirma sentencia de la Corte de Apelaciones de Santiago, 28 de marzo de 2018, Rol N ${ }^{\circ} 16.313-2018$ ).

Corte Suprema, 26 de noviembre de 2018, Rol N 6.109-18 (revoca sentencia de la Corte de Apelaciones de Santiago, 23 de marzo de 2018, Rol N ${ }^{\circ} 11684-2018$ ).

Corte Suprema, 10 de diciembre de 2018, Rol No 20502-2018 (confirma sentencia de Corte de Apelaciones de Santiago, 2 de agosto de 2018, Rol N ${ }^{\circ} 46441$ 2018).

Corte de Apelaciones de Santiago, 3 de septiembre de 2018, Rol N 51.0532018.

\section{c) Normativa}

Constitución Política de la República, 1980.

Declaración Universal de los Derecho Humanos, 1948.

Pacto Internacional de Derechos Económicos, Sociales y Culturales, 1966.

Pacto Internacional de Derechos Civiles y Políticos, 1966.

Convención sobre la eliminación de todas las formas de discriminación contra la mujer, 1979.

Convención Americana sobre Derechos Humanos, 1969.

Código Civil.

Ley de Matrimonio Civil N 19.947, 2004.

Decreto Ley $\mathrm{N}^{\circ}$ 1.094, del Ministerio del Interior, 1975.

Decreto Supremo N 597, del Ministerio del Interior, 1984.

Decreto con Fuerza de Ley $N^{\circ}$ 2.128, del Ministerio de Justicia, 1930. 